\title{
The Research on the Product Humanization Model Based on the Evolution of Consumer Purchase Pat
}

\author{
Na Tao \\ School of Economics and Management, Xi'an Technological University, Xi'an 710021, China
}

\begin{abstract}
Digital economy gives new connotation to business model. In the process of business model changing from vertical to horizontal, from exclusive to inclusive, and from individual to social, the central activity of enterprise marketing should be transferred to how to actively interact with consumers, so that consumers can more participate in the process of enterprise marketing value creation. This paper focuses on the model of consumers' participation in marketing value creation. Firstly, this paper studies the basic model of consumer purchase path evolution, and proposes $5 A+1 D$ model based on the basic model. Then, based on the 5A+1D model, an important carrier for consumers to participate in the value creation of marketing is proposed: the product humanization model. Secondly, the paper analyzes the ideal migration mode of consumer purchase path under humanistic products: "W" model, which finally reaches the balance at both ends of 5A+1D model. Under the ecological background of open innovation, this paper extends the chain of consumers' purchase path and realizes the co-creation of consumers and enterprises' value, and designs a human-oriented product model based on the chain of consumers' extended purchase path. The W model achieves the balance between the beginning and the end of the consumer purchase path model, which provides a theoretical basis for the intervention points of enterprises on the overall consumers' purchase path.
\end{abstract}

Keywords: Purchase path 4.0, Product humanization, Displacement rate, "W" model.

\section{Introduction}

The Internet and mobile devices as interactive infrastructures make today's world highly connected. Connectivity has a profound impact on today's world, where vertical, exclusive, and individual power is being replaced by horizontal, inclusive, and social power. With the transformation of the three rights, the relationship between enterprises and consumers has undergone profound changes. The era in which enterprises dominate marketing communication has passed with the integration of interconnection. It is also because of the integration of interconnection that social network relationships between people are established, and the social conformity psychology of consumers is becoming increasingly prominent. Consumers gradually make decisions in a horizontal way. They pay more and more attention to the opinions of others and are willing to share their own opinions. Consumers communicate and interact with each other to form their understanding of products. The interactive decision-making among consumers will eventually form social effects.

There is often a big gap between the social effect of consumers and the expectation of enterprises. In fact, this gap will be intensified with the high degree of connectivity, and the effect of connectivity will be more obvious with the spread of cheap smart phones. Users are no longer passively accepting product promotion and marketing, and they are no longer single-directional inputs of marketing behavior. The powerful information flow among customers makes the environment for enterprises to live in transparent and real. The possibility of diverting user feedback, false publicity and covering up stains is greatly weakened by the information flow of customers. With the continuous development of the breadth and depth of interconnection, the interconnection will develop into social interconnection. At this time, the user group will have a higher degree of interconnection, and the enterprise will be placed in a completely transparent environment. Good credibility and reputation will be the criteria for the survival and development of the enterprise.

In the context of high interconnection, based on the evolution of the dualistic relationship between enterprises and consumers, this paper studies how to integrate the behaviors of consumers and enterprises, and how to find the intersection between the behaviors of consumers and enterprises. Article, from the perspective of the consumers to purchase path analysis, analysis of the evolution of the consumers to purchase path model, from put forward in the evolution model of consumer behavior between enterprise and the intersection of the carrier, and finally analyzes the intersection vehicle with the product characteristics, to final consumers and companies as a whole, realize the coordinated development of the binary relation.

\section{The Basic Model of Consumer Purchase Path Evolution}

Consumer purchase path is based on consumer behavior. Bitta \& Loudon (1984) believes that consumer path is the decision-making process and physical activity of people when they are engaged in the evaluation, acquisition, use and disposal of products or services. The American Marketing Association defines the concept of consumer behavior as the dynamic interactive process of perception, cognition, behavior and environmental factors, which is the behavioral basis of human trading activities (Liyun, Fanrong, Xiuju, 2004). Drucker (2013) proposed that consumer behavior changes based on the dynamic changes of society, market and technology, and the internal behavior of consumer behavior is the result of the interaction of multiple factors. Tsaietal proposed that consumer behavior should be regarded as a complete process, including the decision-making process before purchase and the purchasing behavior process, and the decision-making process before purchase and the purchasing behavior are mutually constraining. Fishbeinandajzen (1975) put forward the model framework model of the theory of 
rational behavior of consumers: there are two ways to form consumers' actual actions: first, belief and evaluation affect behavioral attitude, then affect behavioral intention, and finally actual action; The other path is that normative beliefs and obedience motivation affect subjective norms, and then affect behavioral intentions, and finally actual actions. An \& Yanhua (2014) studied and discussed the willingness of smartphone users to use the reverse $\mathrm{O} 2 \mathrm{O}$ consumption model in the context of mobile E-commerce by using the theory of consumer rational behavior. Peslak, Ceccucci, Patricia (2010) showed that when using instant messaging tools, people's behavioral attitudes and subjective norms are significantly positively correlated with behavioral intentions. Ajzen (1991) proposed that the more individuals perceive the resources and opportunities they possess, the stronger the control of perceived behaviors based on reduced obstacles.

The role replacement path model of consumers is based on the purchase path model of consumers. Heinszmgoldmann proposed the initial AIDA model of the consumer purchase path model: attention, interest, desire, purchase. The AIDA model describes the initial consumer purchase behavior in a general environment. Derekrucker believes that the purchase behavior should not be the end point in the purchase path of consumers. Based on the loyalty factor of consumers, the purchase end is extended to the repurchase behavior, and interest and desire are combined into attitude. Therefore, the 4A model is formed: understanding, attitude, behavior and repurchase. In the $4 \mathrm{~A}$ model, the contact point and control point of the entire purchase path of the enterprise to the consumer are relatively strong.

With the integration of connectivity, the interaction costs of enterprises, employees, users and the public are reduced, the barriers to market entry are lowered, and the mode of enterprise competition is changed from zero-sum game to multi-party integration. The time mobility and space mobility of consumers are enhanced with the integration of interconnection, and customer behavior has undergone significant changes. The Internet, the basic carrier of customer behavior, becomes the bridge between users and products, and further forms a high degree of social interconnection between user groups and user groups. In this case, the closed 4A model needs to introduce interconnectivity intervention variables to form new customer paths. Philipkotler proposed a $5 \mathrm{~A}$ model of consumer purchasing path.

In Model 5A, the involvement of interconnection factors opens the causal relationship of attitude in 4A. Attraction will first form through personal experience and the contact point of the enterprise, that is, the front end of "attitude" will be formed through the interaction between oneself and the enterprise: attraction. Connectivity enhances social influence between people, forms the interaction between users themselves and society, and forms the back end of "attitude": inquiry. Finally, through the interaction of attraction + inquiry, that is, "user + enterprise + society", the attitude of consumers will be formed, and finally the purchase behavior will be formed. The second mechanism of interconnection intervention is that $5 \mathrm{~A}$ model users replace $4 \mathrm{~A}$ model's repurchase, which is based on the fact that interconnection expands the area of influence of customer loyalty, both in terms of the breadth and depth of influence. The evolution model of specific consumers' purchase path is shown in Figure 1.

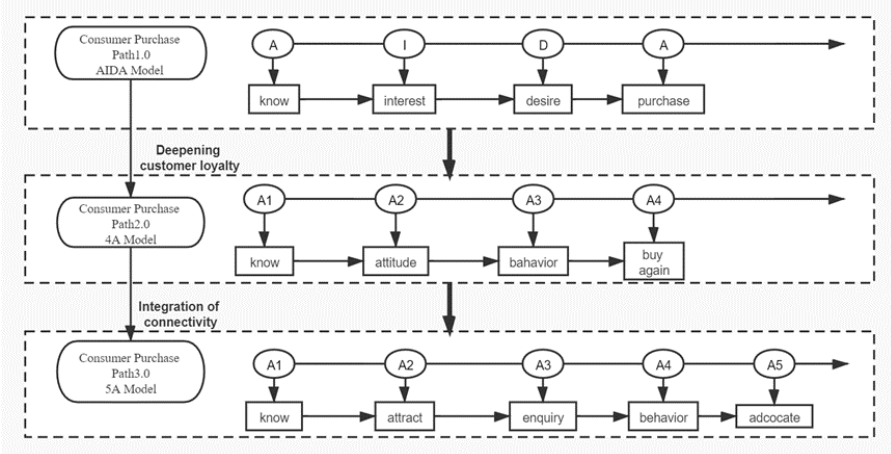

Figure 1: Basic model of consumer purchase path evolution

\section{Consumer Buying Path 4.0: 5A+1D Model}

With the deepening of customer loyalty and the integration of interconnection, the purchase path of consumers has evolved from the 1.0 AIDA model through the 2.0 4A model to the 3.0 $5 \mathrm{~A}$ model. On the basis of the $5 \mathrm{~A}$ model, how to intervene in product responsibility and consumer responsibility resonance behavior, expand the basis of consumer participation in products, and realize the cycle of purchase paths. Therefore, based on changes in the environment where responsibility and consumer responsibility resonate, we propose a consumer purchase path 4.0: 5A+1D model. See Figure 2 for details.

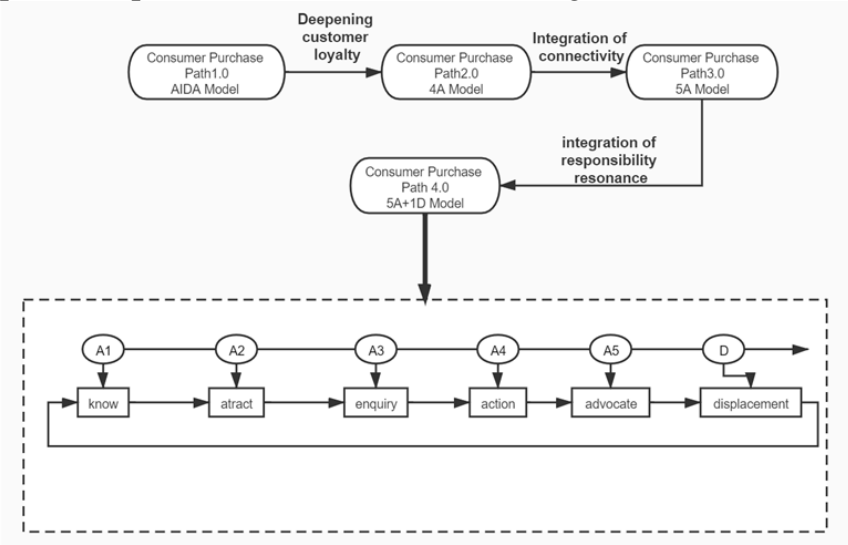

Figure 2: Consumer Purchase Path 4.0:5A+1D Model

On the basis of the 5A model, advocating products are not the end of the consumer's purchase path. It must change from passive advocating products to active advocating products, and from the role of consumers to the dual roles of consumers and participants. When the responsibility of the product stimulates the resonance of the consumer's responsibility, the consumer will become the promoter of the product and the practitioner of responsibility. With responsibility resonance as a catalyst, consumers will replace their own roles and become closely connected with the product. When consumers replace the product promoters, they will be more fully involved in the design, production and operation of the product. It will start a new round of $5 \mathrm{~A}+1 \mathrm{D}$ models, and through iterative reactions, to derive more participants.

In the context of digital anthropology, the influence of $\mathrm{F}$ 
(family, friends, and fans) economy on consumers' decision-making behavior is more important. With the integration of a high degree of interconnection the contacts of enterprises in the purchase path of consumers have become inaccessible, and the uncontrollable factors and uncontrollable scope of enterprises have gradually increased. The influence of externalities is infinitely amplified in the entire interconnection pattern. Producers should build $+1 \mathrm{D}$ fields, and $+1 \mathrm{D}$ is more conducive to exploring the potential needs of customers. Consumers in the $+1 \mathrm{D}$ field can enter consumers' real communities and online communities with dual identities, engage in dialogue with customers, conduct personal research, conduct customer relationship management, form a high degree of resonance with customers, achieve empathy with consumers, and discover the deepest needs and desires of customers.

\section{Research on Product Humanization Model}

\subsection{Product Humanized Model}

The circular path is realized in the $5 \mathrm{~A}+1 \mathrm{D}$ model, but what characteristics should the carrier product of the circular path have. Based on the $5 \mathrm{~A}+1 \mathrm{D}$ model, a product humanization model is proposed. In order to analyze the structure of the product humanization model. Based on the consumer purchase path 4.0:5A+1D model. Based on the intersection of the end point and the starting point: the replacement factor, the replacement rate indicator is introduced. The replacement rate indicator measures a company's ability to convert brand awareness into brand engagement. The replacement rate indicator is used throughout the $5 \mathrm{~A}+1 \mathrm{D}$ model and is measured by the following formula:

\section{displacement rate $=$ \\ $\frac{\text { attraction }}{\text { know }} \times \frac{\text { enquiry }}{\text { attraction }} \times \frac{\text { action }}{\text { enquiry }} \times \frac{\text { advocate }}{\text { action }} \times \frac{\text { diaplacement }}{\text { advocate }}$}

On the one hand, the replacement rate index reflects the degree of transformation from the previous stage to the next stage in the $5 \mathrm{~A}+1 \mathrm{D}$ model. On the other hand, it disassociates quantitative indexes with qualitative variables to establish a foundation for the humanized model of the final product. Analyze the structure of the replacement rate index. Attraction/understanding indicates the conversion rate from understanding to attraction, and the level of conversion rate indicates the attractiveness of the product. Inquiry/attracting means the conversion rate from attracting to inquiring, in which the product plays a key role in stimulating the curiosity of customers. Inquiry/action represents the actual behavior of the customer, that is, the degree of fulfillment of the customer's commitment to the company. Support/action characterizes the affinity of the product. When the affinity of the product is higher, the ratio of support/action is higher. Replacement/support represents the strength of the product's responsibility to stimulate consumer resonance. When the product's responsibility stimulates consumer's resonance, the consumer's replacement level is higher. Based on the above analysis, this article condenses the five indicators of product attractiveness, customer curiosity, commitment fulfillment, product affinity and product responsibility as the key factors to increase the consumer replacement rate. Based on product attractiveness, customer curiosity, commitment fulfillment, product affinity, and product responsibility, this article puts forward a product humanized model of "beauty, intelligence, physicality, labor, and morality". See Figure 3 for details.

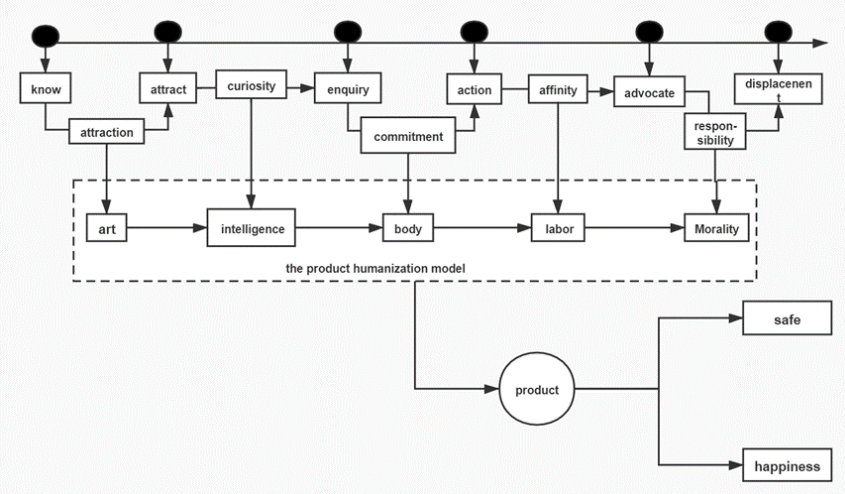

Figure 3: The product humanization model

The beauty of the product is the first link in the human-oriented model of the product. "Beauty of Products" is committed to improving the attractiveness of products and improving the conversion rate of product understanding to product attraction. The beauty of products is mainly reflected in the well-designed LOGO and creative advertising language, as well as exquisite product design and excellent customer experience design. The initial beauty is used to attract the attention of consumers, to lock consumers, and to input products into the human-oriented model. The second link of humanization model is "product intelligence". "Product intelligence" is the golden key to open the curiosity of consumers. Piaget proposed that consumers' curiosity is a function of consumers' sense of lack, and the functional relationship between the two presents an inverted U-shaped relationship. Therefore, in the design of "product intelligence", it is necessary to seek the reasonable range of consumers' sense of loss, and find the threshold between consumers' expectation and their reality level, At the threshold level, by giving product technology elements, improving the intelligent level of products, stimulating consumers' curiosity, opening up consumers' social networks to form an inquiry mechanism, on the one hand, to increase consumers' mobility, and on the other hand, to find more contact points in the social network structure of known consumers.

The third link of the humanized model is the body of the product. "Product body" is the key to improve customer commitment. The "body of the product" refers to the core function of the product, i.e. the durability of the product. A high level of connectivity reduces the losses caused by information asymmetry and quality uncertainty. Therefore, the core functions of the product should be shaped in a transparent and true way, so that consumers can quickly capture the quality information of the product. Shorten the decision-making time from inquiry to action and improve the conversion rate from inquiry to action. The fourth link of humanization model is "product labor". "Product labor" is a powerful guarantee to build product affinity, which is conducive to the transformation from action to support. "Product labor" is mainly to narrow the psychological distance with consumers. Communicate with customers regularly through multiple media channels, have the courage 
to have a dialogue with customers, understand their real demands, and solve their practical problems.

The fifth link of humanization model is "virtue of product". "Product morality" is a key link in the transformation of the role of consumers, realizing a powerful leap from passive support to active participation. Companies must consider ethical standards in every aspect of their business decisions. Ethical business practices should be regarded as a magic weapon of operation, and the production and building of ethical products and brands should be regarded as their core competitiveness. Ethical products mainly show that the product bears personal responsibility and social responsibility, it has effectively solved people's internal problems and external social problems, and produced a strong externality. The connecting subject of internal responsibility and external responsibility is consumers. When consumers purchase and use the product, the satisfaction of individual needs causes consumers to have a strong psychological amplification effect, and consumers will push the product to people in need, and will participate in it with a strong sense of mission and responsibility. Through the input of product humanization model, the final output product of product humanization model should be the product that makes people feel safe and happy. When products have human nature, in the highly interconnected pattern, the positive effect will spread and spread among people, products and products, and products and people.

(2) Ideal migration mode of consumer purchase path under the humanized product: "W model"

Ideal migration mode of consumer purchase path under the humanized product: $\mathrm{W}$ model in $4 \mathrm{~A}$ model, customer behavior is funnel-shaped, and the number of customers gradually decreases with the advance of purchase path. Understanding the transition to attitude will lose some customers, and from attitude to behavior customers are also gradually lost, to the final re purchase behavior due to the role of various factors compared with behavior customers is also reduced. In the whole process of funnel loss, the enterprise's marketing behavior plays a key role in the intervention of user behavior, and the enterprise's key contacts are under its control. However, the elastic space of enterprise contacts is limited. Therefore, customers are constantly lost along with the funnel model. With interconnectivity and the subjectobject bidirectional integration of corporate responsibility and consumer empathy, this paper proposes the "W" model of the ideal migration pattern of consumer purchase path, as shown in Figure 4.

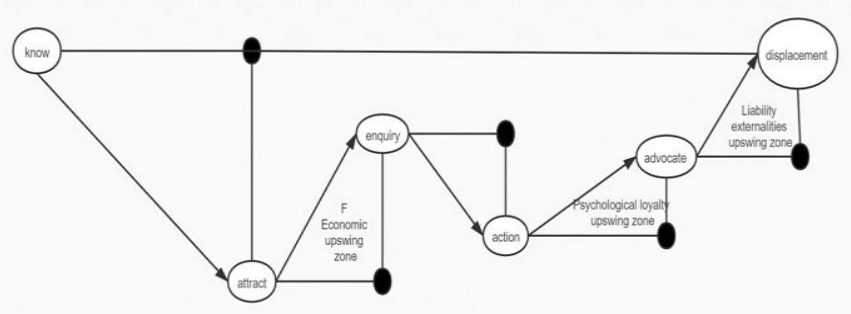

Figure 4: The ideal migration path "W" model

In the "W" model, the two descending areas of "W" are the "know-attract" region and the "inquiry-action" area. The two rising areas of "W" are "attraction-inquiry", "action-support" and "support-replacement" links. The rising domain of "attraction-inquiry" originates from the rising triangle of $\mathrm{F}$ economy, and customers will form an inquiry mechanism in their own social network to attract their own products and brands. Customers' social networks include friends, family, fans and online communities. The inquiry mechanism will expand the contact between the product and the consumer, and the contact will spread through the next node, where the $\mathrm{F}$ economic growth zone will form an infinite network connection. As far as enterprises are concerned, do not try to convince consumers at one stage, but to encourage the establishment of consumer inquiry mechanism at one stage, on the one hand, it is based on consumer empathy to do the layout, on the other hand, it can train potential two-stage customers.

The rising domain of "action-support" comes from the rising area of psychological loyalty. The main dimension of psychological loyalty which is different from the actual purchase lies in the purchase frequency based on the importance of the product and the frequency of use, and the purchase possibility based on regional reasons. There will be an increase in the area of support based on psychological loyalty than in the area of action. Therefore, enterprises can not ignore the cultivation of psychological loyalty based on the characteristics of products and consumers. It is necessary to do a good job in the psychological maintenance of consumers and enhance their psychological loyalty. The rising domain of "support-replacement" comes from the rising area of responsibility externality. The morality of the product will stimulate the sense of responsibility in the hearts of consumers, and the sense of responsibility will spread rapidly in the social network of consumers. The externality of responsibility has a positive indirect network externality effect. The more consumers are replaced, the stronger the product promotion is, and other consumers who do not enter the network will gradually enter the network out of curiosity about the product. The more people enter the network, the higher the replacement rate is, and the rising triangle of the externality of responsibility will be more significant.

From the "W" model of the ideal migration path of consumer role replacement, we can see that the "understanding-attraction" region is dominated by the behavior of products and enterprises, the positioning of products and the deviation of enterprises' marketing activities will lead to the decline of understanding attraction. At this time, enterprises can increase the number of consumers through the $\mathrm{F}$ economic growth triangle of "attraction-inquiry". The subsequent "inquiry-action" behavior shows another round of decline, which is due to the time lag of the formation effect of the inquiry mechanism on the one hand and the negative effect of the inquiry mechanism on the other hand. In the next "action-support" and "support-replacement" links, due to the rising zone of psychological loyalty and the rising area of responsibility externalities, the number of consumers will increase rapidly until we return to the initial state of understanding and achieve the balance between the two ends of the "W" model. 


\section{Conclusion}

With the integration of connectivity, the three major rights have changed from vertical, exclusive, personal behavior to horizontal, inclusive and social behavior. The behavior of the relationship between enterprises and consumers has undergone profound changes with the transformation of the three major rights. Consumers rely more on $\mathrm{F}$ factors to make horizontal decisions, and the interactive decisions between consumers finally form social effects. This powerful social effect makes the enterprise lose the leading power of marketing communication, and the enterprise is placed in a transparent and real living environment. This paper studies how to integrate the behavior of consumers and enterprises, starts with the analysis of consumers' purchase path, deepens the consumers' purchase path, and puts forward the humanistic model of products based on the new consumer purchase path. To achieve the coordinated development of the dual relationship between producers and consumers. The conclusions are as follows:

This paper puts forward the evolution model of consumer purchase path: the AIDA model of consumer purchase path 1.0 evolves to the $4 \mathrm{~A}$ model of consumer purchase path 2.0 through the deepening of customer loyalty, from the integration of interconnection to the $4 \mathrm{~A}$ model of consumer purchase path 3.0, and from the integration of responsibility resonance to the $5 \mathrm{~A}+1 \mathrm{D}$ model of consumer purchase path 4.0. In the $5 \mathrm{~A}+1 \mathrm{D}$ model, with responsibility resonance as the catalyst, consumers change their roles and are closely related to the product. Open the structure of the replacement rate and refine the product attractiveness, customer curiosity, commitment, and product affinity and product responsibility as the key factors to improve the consumer replacement rate. Based on this, a product humanization model of "beauty, intelligence, physique, labor and morality" is put forward. Through the input of the product humanistic model, the final output product should be the product with sense of security and happiness.

Based on the humanistic product model, this paper puts forward the ideal migration model of consumer purchase path: "W" model. The descending region focuses on the "understanding-attraction" area and the "inquiry-action" area, while the rising region focuses on the "attraction-inquiry" of the F economic rising triangle, the "action-support" of the rising area of psychological loyalty, and the "support-replacement" of the rising area of responsibility externalities. By bridging the ascending zone and descending zone, the balance of the vertices at both ends of the "W" model is achieved.

\section{Declarations of Interest}

The authors declare no conflicts of interest.

\section{Acknowledgement}

This research was funded by the National Natural Science Foundation of China, grant number 71804139. This research was funded by the soft science in Shaanxi, grant number 2020KRM030.This research was funded by The Youth Team of Shannxi Universities.

\section{References}

[1] An T, Yanhua J. Research on Consumers' Intention to Use in Reverse O2O Model - Based on the Perspective of Consumption Value Theory and Rational Behavior Theory[J], 2014, 27(04): 86-90.

[2] Ajzen, I.. The Theory of Planned Behavior[J]. Organizational Behavior \& Human Decision Processes, 1991, 50(2): 179-211.

[3] Bitta, A.D., Loudon D.. Consumer Behavior: Concepts and Applications[M]. New York: Mc Grew-Hill, 1984.

[4] Drucker, P.F. The Theory of the Business[J]. Harvard business review, 2013, 35(1): 9-11.

[5] Fishbein, M., Ajzen I. Belief, Attitude, Intention and Behavior: An Introduction to Theory and Research[M]. New Jersey: Addison-Wesley, 1975.

[6] Liyun F, Fanrong M, Xiuju J. Consumer Behavior[M]: Economic Management Press, 2004.

[7] Peslak, A., Ceccucci, W., Patricia S.. An Empirical Study of Instant Messaging (IM) Behavior Using Theory of Reasoned Action[J]. Journal of Behavioral and Applied Management, 2010, 11(3): 263.

[8] Tsai, M.T, Chen K.S, Chien J L. The Factors Impact of Knowledge Sharing Intentions: the Theory of Reasoned Action Perspective[J]. Quality \& Quantity, 2012, 46(5): 479-1491.

\section{Author Profile}

Na Tao, $\mathrm{PhD}$, Associate Professor, Master Supervisor, Research Field: Technology innovation and reliability management. 